\title{
Living with Plants or Leaving Plants? A STEM- based Teaching Approach
}

\author{
Papadopoulou Foteini \\ Postgraduate Student in MSc STEM in Education, \\ University of Patras
}

\author{
Vasilou Myrto- Panagiota \\ Postgraduate student in MSc STEM in Education, \\ University of Patras,
}

\author{
Georgiou Martha \\ Laboratoyry Teaching Staff, \\ Department of Biology, \\ National and Kapodistrian University of Athens,
}

\begin{abstract}
The current teaching approach deals with a phenomenon known as Plant Blindness and the way that the younger students' alternative ideas regarding this phenomenon can be overturned through a STEM project. Based on the principles of STEM education, this project consists of phases the main goals of which are divided into two parts: initial detection of the alternative ideas that young students already have and subsequently decomposition of these ideas by using practical and hands-on activities. The target group of the project is primary school students from the first grades, as the concepts of living and non-living things have been proven to be a challenging task at this age that children get in contact with various natural world's issues trying to give interpretations
\end{abstract}

Key Words: Plant Blindness; Biology; STEM education; project; primary education

\section{INTRODUCTION}

Children, from a young age, have an innate curiosity about themselves and the world around them. Trying to satisfy it, they construct representations and conceptual schemes that are often incorrect or very generalized (Christidou, 2015). In every field of Science, young kids are able to understand very specific and premature concepts, since their developmental status does not allow them the learning of more complex concepts (Halkia, 2016). Thus, it is of great importance to make a wise choice of the subjects in which they are able to be engaged in every phase of their cognitive development and also to stay away from stereotyped views that create negative feelings and/ or fear of being involved in Science (Halkia, 2016).

Much research has been conducted about the alternative ideas of young children, that attended pre-school and first grades of primary school, regarding what is considered to be included in the category of the living things and what is not. The children's alternative ideas upon this matter, as well as the arguments they use to justify them, are to be found as research questions both in former studies like the ones of Gelman \& Gottfried (1996) and Bullock (1985) and in more recent ones (Akerson, Weiland \& Fouad 2015; d Villarroel \& Infante 2014). The results showed that the lack of understanding both about animism and the characteristics that define the living organisms, are issues that have been encountered in younger children's beliefs for many decades. However, there is much research not only on studying proofs of the existence of these alternative ideas, but also on probable activities, lesson plans and projects that aim to transform these ideas. Martínez-Losada, GarcíaBarros \& Garrido (2014), Çì (2015), Amprazis \& Papadopoulou (2015) have conducted research on the above topics.

From living- non living to plant blindness

Educators or people who work with young kids and aim to teach them biological topics, should check the level of educational demands that young kids can reach in this field (Smyth \& Nosek, 2015; Carli et al., 2016). This means that the age and the spiritual level of each phase of development have to be taken into consideration before selecting the subjects to be taught. Children learn and understand things taught in a gradual difficulty, so the research mentioned above explains which biological terms they might come in contact with depending on their age. One of the main misinterpreted issues is the notion of living and nonliving organisms (Zogza, 2015). More specifically, young children cannot fully understand the elements that render an organism living or non-living. As a result, it is very confusing for them to place plants and animals in the category of living beings. They recognize and are aware of common attributes between these two and the humans (e.g. animal movement, food/nutrition, etc.). However, they are not able to understand that they all belong to the same category of living beings, especially plants (Zogza, 2015). This knowledge comes to them gradually.

In fact, for both adults and young children it is considered extremely difficult to observe plants, a phenomenon called "plant blindness" (Wandersee \& Schussler, 2001). According to Wandersee \& Clary (2006), people who are unable to understand the plant's living status are considered: a) to be unable to see, observe or capture plants in their daily lives, b) to believe that plants are merely a landscape for animals, (c) to misinterpret the necessity of plants for lifelong and daily use; (d) to be unable to appreciate the beauty of plants and their essential role in the biogeochemical cycle, (e) not to understand and interpret the properties of plants or (f) to have no experience in cultivation and plant growth.

From all the above mentioned, it is clear enough why it is important that everyone, even from a young age, could be able to recognize plants as living beings. 


\section{STEM education}

STEM education has been highly discussed over the past few years. One of the first founders of STEM framework is Dewey, whose ideas influenced science teaching for a long period of time (Glancy \& Moore, 2013). Nowadays, when we refer to STEM education, we refer to teaching approaches which combine four components (Science, Technology, Engineering and Mathematics), so that students can be holistically engaged in problems of the real world and not in single cognitive subjects (Glancy \& Moore, 2013). According to the National Research Council (Holmlund, Lesseig \& Slavit, 2018), the three basic objectives of STEM education are: 1) the raise of the number of scientists in science, 2) the empowerment of human capacities in these fields and 3) the improvement of all citizens' scientific literacy.

Consequently, we believe that STEM education offers the suitable ground to the young students in order for them to be able to clarify the confusing and abstract concepts of "living - non-living" and specifically integrate plants in the living beings' group. The investigation of such a genuine question for kids through STEM education contributes to a more holistic understanding of the world around them and to a more critical way of thinking.

\section{METHOD}

\section{a. The objectives of the teaching approach}

The main aim of the current project is for students to get in contact with the field of Biology from an early age and to be exposed to certain basic concepts, such as those of living and non-living organisms. We pursue the children to comprehend mathematical concepts (classification, measurement units of length and weight, concept of time etc.), concepts of the natural world (e.g. energy, heat) and to put into implementation technological skills (computer operation and programming) and engineering skills (construction of a greenhouse).

\section{b. The rationale of the teaching approach}

But how can STEM education contribute to this project and/or why is the use of this type of education necessary according to the description of its components? Starting with Science, it is obvious that students will get in touch with basic biological concepts and this will not happen only during the activities. These concepts are the basis of the original problem of the project which kids will be engaged in. In order for the pupils to understand the characteristics of living organisms and specifically the life cycle of plants, regardless of the environmental conditions and the duration of the project, the construction of a greenhouse will be really helpful. This way, children will have the opportunity to observe in a daily basis both the concepts and the phenomena described in each previous activity. Consequently, it is obvious that while creating a greenhouse, students as young engineers will have to choose between various options/building materials which will be preferable for their successful construction. Simultaneously technological applications consist a great part of our project not only through the use of ICT (e.g. video projections), but also because its importance is based on two broader axes. On the one hand, the use of technological tools will help to complete the project successfully (e.g. use of microscopes for leaves' surface observation) which probably could not be achieved through another way. On the other hand, an effort for laying foundations for computer programming through the use of Arduino and the Scratch programming environment will take place. In more details, hygrometers, which in biological laboratories are normally used as specific tools that can measure humidity, now can be substituted for school use by mechanisms like Arduino or by other types of robots with humidity sensors. Moreover, Mathematics plays a significant role in our project providing different options of calculating and measuring quantities arithmetically. However, through various activities, children have the opportunity to learn and study important mathematical concepts and relate them to their environment. For example, the transition from two to three dimensions, which will occur through our project's activities, will contribute to the students' spatial perception.

\section{c. The overview of the teaching approach}

$\boldsymbol{I}^{\text {st }}$ phase: Upon the beginning of the project, the aim of the teacher/educator is two-dimensional. At first, it is essential for the students to raise awareness about plants and to start posing questions relating to this topic. On the other hand, it is necessary for the teacher to elicit students' alternative ideas about plants as afterwards he/she will be able to adjust the activities accordingly to the needs and knowledge level of the students' group. Therefore, students will be engaged in "knowing the plants" activities and card games, focusing in the features of living plant beings as an enrichment of what they can already recognize by their experience on human and/or animal characteristics. Hence, students will clarify the definition of living beings in general.

$2^{\text {nd }}$ phase: At this stage, the teacher deals with how the properties of living beings are to be found in plants. Some of the properties were chosen to be studied at a greatest extent, while others will be mentioned without further details. The criterion for this choice was the age and the cognitive level of children in this developmental stage. In particular, it would not be easy to deepen too much in attributes that are accompanied by tricky concepts and have effects that are not easily observable (e.g. respiration), while other properties such as development - are easier to understand because they are closer to the experiences of children and are perceived through their senses.

Project's activities begin by highlighting the ability of growth, as its effects are distinct and easily recognized by children. In particular, children from their early years can notice that plants grow over time and do not stay in a stable form. Initially, a related video will be displayed aiming to provide food for thought and further discussion so as to elicit the pre-existing 
knowledge of children about the growth issue. Subsequently, students, through the experimental process (planting in small pots), will observe in practice the conversion of the seeds into plant and the relevant factors. They will keep a record of their observations on how much (or not) each plant grew, avoiding further explanation and documentation which will be misunderstood by so young children. A next step - activity on plant growth will be a LEGO game. This activity will allow a first contact with the scientific term "cell" in order to inform students that this is the basic and the smallest unit of life. Hence, we will ask them to create a LEGO flower and then we will ask them to decompose it to its ingredients, the bricks - cells. Finally, students will use microscopes for further familiarization with scientific instruments and for enhancement of conceptual understanding.

The ability of nourishment and photosynthesis will be the step to follow. Obviously, it is not possible for young children to fully understand the mechanism and the chemical processes that take place during photosynthesis, but this is not our goal anyway. The challenge is for the children to come in contact with scientific concepts and phenomena, which they will go more in depth in later school ages. At this stage, the main goal is a comparison between the need of nourishment as it is known for humans and animals and how the same need appears in plants. An accompanying video will be necessary as the process cannot be directly observable. After that, a short presentation related to photosynthesis and the factors from which is affected, is displayed to students. Students will then return to the previous experiment of plant growth in pots to document on a more scientific basis why plants grow and how they are affected by the presence of each factor.

Next comes the ability of respiration, which is invisible by humans and thus it is considered to be complicated enough. The initial activity of this phase will be a video projection that schematically represents the process of respiration in order to simplify it as more as possible. Moreover, for the first time in this project, students will be able to get in contact with a scientist working in this field (research on plants), who will explain to them the process of respiration more thoroughly, and at the same time students will have the opportunity to find out how a scientist actually works. More specifically, the invited scientist will not just talk to the children but they will all examine together various leaf surfaces and plant pieces using microscopes.

Movement is one of the main features that prevent the inclusion of plants in the category of living beings by students. This means that students believe that plant do not move at all. After an initial discussion, which will help the teacher detect the ideas on this subject, a pot will be demonstrated to the students. This pot will contain the plant "mimosa", which has intense irritation when its leaves are touched. Subsequently, it can be used to prove the direct (even rudimentary) movement of the plants. However, the heart of this activity is the phenomenon of phototropism and not the irritability that characterizes particular plants. Pots that the kids created in previous activities will be used for this phenomenon to be observed.

Finally, we will dare to give a short reference to reproduction. This short reference is related to the young age of students and to the careful handling we should do. The main part of the activity will take place in an outdoor area, away of the school environment, where children will again interact with specialists. However, before this, a preparation will be needed especially concerning the interview that the students will conduct. More precisely they will interview the director of the place visited. The aim of this activity is not only for the children to be informed about plants' reproduction, but also to place in social background the knowledge they gain at school, even from their early age.

$3^{\text {rd }}$ phase: Once the basic concepts have been approached through the previous activities, children will be asked to gather all the collected information so that they will see all the distinct features of life together, features that plants really have as living beings. In particular, at this point they will create their own greenhouse to implement practically everything they have studied earlier. To create a greenhouse, knowledge and skills from the field of Mathematics will be necessary in addition with biological knowledge. Students will create the parts of their greenhouse from scratch, they will make measurements of different types (lengths, weights, time, etc.), they will make shapes, they will make a transition from the two-dimensional shapes to the three-dimensional ones etc. Moreover, they will work as young engineers, experimenting with the properties of the building materials that they will be given, making comparisons between them and deciding the ideal ones for their construction. Finally, as scientists cannot work without the necessary technological equipment, students, as young scientists, will use robotic structures such as hygrometers. It is obvious that the age of the kids does not allow us to insist on the creation of these robotic structures by themselves. However, the project aims at setting the first bases concerning programming and ICT and their contribution to scientific achievements.

\footnotetext{
$4^{\text {th }}$ phase : Each project, in order to be complete, should contain both an evaluation part and a presentation one. For this purpose, a quiz was created on an e-learning platform, where students will be asked to answer various questions individually or in groups, so that the educator can find out whether the topics of the project were understandable or/and identify the deficiencies of the students. Through this platform, the educator can have a feedback by extracting statistics about the performance of the students, about the questions that have been answered correctly by each one, about the duration needed for each answer, etc.
} 
Finally, on the part of presentation, students will be free to choose the audience to whom they will address - for example whether the presentation will be exclusively addressed to classmates from other grades and school teachers or a wider event including parents may also take place. After that, they will decide how the presentation will be communicated; they will prepare the relevant communicative material (e.g. posters, invitations, etc.) as well as the presentation material. Of course, once again the teacher will be supporting and facilitating towards students by intervening only when this will be absolutely necessary for any process to run in a smooth and productive way.

\section{d. The implementation of the teaching approach}

This paper describes the plan of a STEM project that hasn't been fully tested yet. It is a proposal on how to teach young learners about a biological issue regarding living and non-living with focus on Plant Blindness.

According to this plan, this project is expected to last about 3-4 months. This duration is calculated for students of the first grades of primary school $\left(2^{\text {nd }}\right.$ and $3^{\text {rd }}$ grade). However, even though we have planned it on paper, its implementation will highlight some weak points of the design which we will take into consideration to improve this first project version. For example, it is expected that during the implementation there will be some characteristics of the plants, that won't be easily identified: reproduction and respiration. In that case, the relevant activities will be reformed in a more efficient direction. This kind of feedback will be really helpful to future amelioration of the approach proposed.

As already mentioned this project refers to $2^{\text {nd }}$ and $3^{\text {rd }}$ grade's students. Ideally, the class should be consisted of 20 students that will work in groups of 4 or 5. Taking into consideration the Greek curriculum for primary education, this project could be embedded in a course named "Study of the environment" which includes chapter with similar concepts as the chosen ones. Alternatively the flexible zone, which could include any subject, could host the project. Of course, there are similar opportunities in primary education's curricula of every country.

\section{DISCUSSION - CONCLUSIONS}

The four components of STEM education - the basis on which this project was designed - are believed to provide the appropriate scope for young learners to understand the obscure and abstract notions of "living- non living" and especially to contribute to reduce plant blindness. In this context, the project should be shortly implemented in school as a pilot study so as to give feedback from an executive perspective which will occur in a real class (e.g. corrections, additions, modifications etc). Overall, we will have the chance to evaluate in which level the goals of the project will be successfully fulfilled. In addition we believe that with various changes, such as: the creation of a real greenhouse in the school yard, the construction and programming of the hygrometer, the active involvement in the design of the project's phases by the students, the deeper engagement with the more difficult concepts of reproduction and breathing, this project could be implemented to older students of primary education. Besides, STEM education in Greece is at an early stage and has had limited implementation until now. Hence, it is imperative to develop educational proposals to integrate it in science education even from preschool age.

\section{REFERENCES}

[1] Akerson, V. L., Weiland, I., \& Fouad, K. E. (2015). Children's ideas about life science concepts. Research in early childhood science education, 99-123. Doi: 10.1007/978-94-017-9505-0_5

[2] Amprazis, A. \& Papadopoulou, P. (2015). Investigating and recording the parameters of the Plant Blindness of Teachers and Students: A bibliographic overview. In A. Polizos, D. Schizas, P. Stasinakis\& G. Vardakostas (eds.) Proceedings of the $3 \mathrm{rd}$ Panhellenic Conference "Biology in Education" of the Panhellenic Association of Life Scientists (pp. 151-160). Katerini: Panhellenic Association of Life Scientists.(In Greek).

[3] Amprazis, A. \& Papadopoulou, P. (2018). Attitudes towards plants: Evaluating the intensity of the "plant blindness" phenomenon in Greek primary schools. Proceedings of the XII Conference of European Researchers in Didactics of Biology, Zaragoza, 26/7/2018.

[4] Bullock, M. (1985). Animism in childhood thinking. A new look at an old question. Developmental Psychology, 21(2), 217-225. Doi:10.1037/0012-1649.21.2.217

[5] Carli, L.L., Alawa, L., Lee, Y., Zhao, B. \& Kim, E. (2016) Stereotypes about Gender and Science: Women $\neq$ Scientists Psychology of Women Quarterly, 40 (2), 244-260. doi.org/10.1177/0361684315622645

[6] Christidou, B. (2015). Import. In V. Christidou (Ed.), Educating Young Children in Natural Sciences. Research orientations and pedagogical practices. (pp. 11-54). Kyriakidis Publishers, Thessaloniki. (In Greek)

[7] Çil, E. (2015). Integrating botany with chemistry \& art to improve elementary school children's awareness of plants. American Biology Teacher, 77(5), 348-355. Doi: 10.1525/abt.2015.77.5.5

[8] Gelman, S. A., \& Gottfried, G. M. (1996). Children's causal explanations of animate and inanimate motion. Child Development, 67(5), 1970-1987. Doi: 10.1111/j.14678624.1996.tb01838

[9] Glancy, A.W. \& Moore, T.G. (2013). Theoretical Foundations for Effective STEM Learning Environments. School of Engineering Education Working Papers. Paper 1 https://docs.lib.purdue.edu/cgi/viewcontent.cgi?article=1000\&con text=enewp

[10] Halkia, K. (2016). Teaching natural sciences. Theoretical issues, concerns, suggestions. Pataki Publications, Athens. (In Greek).

[11] Holmlund, T.D., Lesseig, K. \&Slavit, D. (2018). Making sense of "STEM education" in K-12 contexts. International Journal of STEM Education, 5:32, 1-18. https://doi.org/10.1186/s40594-018$\underline{0127-2}$

[12] Martínez-Losada, C., García-Barros, S., \&Garrido, M. (2014) How children characterize living beings and the activities in which they engage. Journal of Biological Education, 48(4), p. 201-210. Doi:10.1080/00219266.2013.849281

[13] Smyth, F.L. \&Nosek, B.A. (2015). On the gender-science stereotypes held by scientists: explicit accord with gender-ratios, implicit accord with scientific identity. FrontiersinPsychology, 6 , 1-19. https://doi.org/10.3389/fpsyg.2015.00415 
[14] Villarroel, J. D. \&Infante, G. (2014). Early understanding of the concept of living things: An examination of young children's drawings of plant life. Journal of Biological Education, 48(3), 119126. Doi:10.1080/00219266.2013.837406

[15] Wandersee, J.H. \& Clary, R.M. (2006). Advances in research towards a theory of plant blindness. Proceedings of the 6th International Congress on Education in Botanic Gardens, Oxford University, The University of Oxford Botanic Garden, $10^{\text {th }}-14^{\text {th }}$ September 2006.

[16] Wandersee, J. \&Schussler, E. (2001). Toward a theory of plant blindness. PlantScienceBulletin, 47(1), 2-8.

[17] Zogza, B. (2015). The characteristics of the intuitive biological knowledge of pre-school children: Conditions and requirements for further development. In V. Christidou (Ed.), Educating Young Children in Natural Sciences. Research orientations and pedagogical practices. (pp. 57-76). Kyriakidis Publishers, Thessaloniki. (In Greek). 